\title{
Newton's Cooling Rate Constant of Liquids for the Relative Assessment for Heat Transport
}

\author{
Fabricio Rodríguez-Acevedo ${ }^{1}$, Stefano Fiore-Álvarez ${ }^{2}$, Melissa Zúñiga-Campos ${ }^{3}$, \\ Bárbara C. Miranda ${ }^{4}$ and Julio F. Mata-Segreda ${ }^{5}$ \\ ${ }^{1,2,4}$ School of Chemical Engineering, School of Chemistry, University of Costa Rica, Costa Rica \\ ${ }^{3,5}$ Biomass Laboratory, School of Chemistry, University of Costa Rica, Costa Rica
}

Correspondence should be addressed to: Julio F. Mata-Segreda; julio.mata@ucr.ac.cr

Received date: 10 April 2018; Accepted date: 15 May 2018; Published date: 26 June 2018

Academic Editor: M. M. Sarafraz

Copyright (C) 2018. Fabricio Rodríguez-Acevedo, Stefano Fiore-Álvarez, Melissa Zúñiga-Campos, Bárbara

C. Miranda and Julio F. Mata-Segreda. Distributed under Creative Commons CC-BY 4.0

\begin{abstract}
An alternative simple method is proposed for the assessment of the ability of liquid materials to transport thermal energy, driven by a temperature gradient. The quantity $J=k_{N} \times \rho \times C_{p}$ for different liquids correlates with the corresponding values of thermal conductivity $(\lambda)$ at $p<$ 0,01 , where $k_{N}$ is the Newton's cooling rate constant of a material of density $\rho$ and heat capacity $C_{p}$. The $J$ values of biodiesel, vegetable oils and petroleum-derived long-chain materials are statistically similar. This finding allows taking advantage of the environmentally friendly characteristics of vegetable oils and biodiesel for thermo-solar and low-enthalpy geothermal applications. The empirical regression equation is $J / \mathrm{kW} \mathrm{K}^{-1} \mathrm{~m}^{-3}=1,5+2,2 \lambda / \mathrm{W} \mathrm{K}^{-1} \mathrm{~m}^{-1}$.
\end{abstract}

Keywords: Biodiesel, vegetable oils, thermal conductivity, geothermal and solar heat transport.

\section{Introduction}

Heat is the transfer of energy across the boundary of a system, driven by a temperature difference between the system and its surrounding environment. At moderate temperatures, the two mechanisms for heat transfer are conduction and convection, but the overall view of the issue is a transfer of molecular kinetic energy from hotter zones to colder zones of the system or to the environment, as stated in the early articles by Bridgman (1923), Osida (1939) and Mohanty (1951).

Cite this Article as: Fabricio Rodríguez-Acevedo, Stefano Fiore-Álvarez, Melissa Zúñiga-Campos, Bárbara C. Miranda and Julio F. Mata-Segreda (2018)," Newton's Cooling Rate Constant of Liquids for the Relative Assessment for Heat Transport", International Journal of Renewable Energy \& Biofuels, Vol. 2018 (2018), Article ID 996542, DOI: 10.5171/2018.996542 
Two common situations are the use of geothermal and solar energy. Fluid carriers are required for the conduction of thermal energy from the hot source to whatever material must be heated.

From a heat-transport point of view, the two key properties of fluid carriers are thermal conductivity $(\lambda)$ and thermal diffusivity $(D)$.

Thermal conductivity is defined by Fourier's law (Constant, 1954):

Thermal flux $=-\lambda \nabla T$

The physical meaning of this parameter is a measure of the ability of a material to conduct heat.

Thermal diffusivity is defined by the so-called heat transfer equation (Constant, 1954):

$$
\begin{aligned}
\frac{\partial T}{\partial t} & =D \nabla^{2} T \\
D & =\frac{\lambda}{\rho C_{p}}
\end{aligned}
$$

The physical meaning of $D$ is a balance between the ability of a material to transport thermal energy $(\lambda)$ and the capacity of storage of thermal energy $\left(\rho \times C_{p}\right)$, this last quantity being dubbed thermal inertia. Thus, $D$ indicates how fast heat is conducted through a particular medium (Salazar, 2003).

It is clear that knowledge of $\lambda$ values is necessary, in order to evaluate the possibility of using certain fluids as heat carriers. Density $(\rho)$ and $C_{p}$ are properties easy to measure, but specialised equipment is needed for the measurement of thermal conductivity. Technical literature may miss the $\lambda$ values of new materials under consideration, or this parameter may be unknown.

We present the proposal to use Newton's cooling rate constant as a property that indirectly allows the relative assessment of $\lambda$ for liquid materials, and the model is applied to petroleum-derived oils, biodiesel and vegetable oils, in order to assess the potential use of the vegetable materials as heat carriers in low-enthalpy geothermal or thermo-solar rigs.

\section{Statement of the Proposal}

Newton's law of cooling indicates that the rate of temperature decrease of hot objects is proportional to the difference between their temperature and the eventual equilibration temperature with the surroundings $\left(T_{e q}\right)$ :

$$
\frac{-d T}{d t}=k_{N}\left(T-T_{e q}\right)
$$

$T=T_{e q}+\left(T_{o}-T_{e q}\right) e^{-k_{N} t}$

$k_{N}$ is the relative rate of cooling of a hot material and indirectly reports on the ease of thermal energy transfer from the system to a surrounding thermal sink, at temperatures where radiation mechanism is not significant. This first-order kinetic constant is a property of the macroscopic geometry of the system (heat fluxional area) and the chemical nature of its constituents, including physical state of aggregation. The rate of temperature decrease is a cognate manifestation of the thermal energy flow that takes place upon cooling of bodies. How rapidly energy flows to the surroundings is an inverse function of the capacity of the system to store thermal energy. From equation $[2 \mathrm{~b}]$, one has that $\lambda=$ $D \times\left(\rho \times C_{p}\right)$. Thus, on intuitive grounds we can propose the quantity:

$$
J=k_{N} \times\left(\rho \times C_{p}\right)
$$

of units $\mathrm{W} \mathrm{K}^{-1} \mathrm{~m}^{-3}$ that gives the volumetric ability of a material to transport thermal energy driven by a temperature gradient that varies with time, in much the same sense as the physical interpretation of $\lambda$. Therefore, a significant correlation must exist between $J$ and $\lambda$ that should allow assessing the heattransport ability of different liquids, without the need of measurement of $\lambda$ itself.

Fabricio Rodríguez-Acevedo, Stefano Fiore-Álvarez, Melissa Zúñiga-Campos, Bárbara C. Miranda and Julio F. Mata-Segreda (2018), International Journal of Renewable Energy and Biofuels, DOI: 10.5171/2018.996542 


\section{Materials and Methods}

\section{Materials}

All pure chemicals were obtained from the stockroom, from different commercial sources. The petroleum-derived oils were from Chevron. Biodiesel samples were gifts from Energías Biodegradables (Costa Rica) and Biodiésel H\&M (Costa Rica). Palm olein was kindly provided by Palma Tica, S. A. (Costa Rica) and Acrocomia oil from Green Integrated Energies (Costa Rica). 2Trifluoromethyl-3-ethoxy-perfluorohexane (Novec $^{\circledR} 7500$ ) was from 3M and a gift from Intel Costa Rica.

\section{Thermal Transport Properties}

The experiments were uncomplicated: 50 $\mathrm{cm}^{3}$ of liquid was placed in rubber-stoppered Pyrex $^{\circledR}$ red line $50 \mathrm{~cm}^{3}$ test tubes (Pyrex catalogue number 7952-25) with a thermometer inserted. The contact area between liquid and tube wall was $125,2 \mathrm{~cm}^{2}$ once the thermometer was inserted. The whole system was heated to $\sim 90{ }^{\circ} \mathrm{C}$ (hot water bath) and allowed to cool down to ambient room temperature against stagnant air.

Newton's cooling constants were determined by following the decreasing temperature of the hot samples along time, and further nonlinear fit of the time-temperature data pairs to the mono-exponential decay model [3b], done with a commercial non-linear fitting computer programme. The measurements were done in triplicate in the controlled environment of the laboratory $\left(22^{\circ} \mathrm{C}-24^{\circ} \mathrm{C}\right.$ and $60 \%$ relative humidity) in the absence of significant air currents.

The value of $\lambda$ for Pyrex ${ }^{\circledR}$ glass is $1,05 \mathrm{~W} \mathrm{~K}^{-1}$ $\mathrm{m}^{-1}$, value that is one order of magnitude greater than for the typical values of liquids. Thus, the barrier for heat flow imposed by the tube wall is small and constant for all experiments done by using the same pieces of glassware. The procedure gives a good approximation of direct heat flow from the hot liquid samples to the surrounding air for all materials studied.

For those materials whose $C_{p}$ were not known, the property was determined by the customary calorimetric procedure (Shoemaker \& Garland, 1968).

\section{Results and Discussion}

Vegetable oils or biodiesel derived from them have no associated problems such as high corrosion of metallic equipment, as is the case of hot aqueous liquids. These renewable organic materials are also of low concern for consequences on occupational or environmental safety such as spills, because they are biodegradable at a minimum of 80 $\%$ in the open environment within a month or two (Demirbaş, 2008; Lutz, et al., 2006; Sendzikiene et al., 2007). But the question arises about their ability to transport heat, compared to long-chain petroleum-derived liquids.

It was stated in the introductory part of this paper that measurement of the thermal conductivity of liquids might not be feasible because of lack of the specific laboratory equipment. This is the case of situations when an approximate but reliable assessment of the ability for heat conduction of a liquid is needed.

We tested our hypothesis of the proportionality of $\lambda$ and $J$ with 19 liquids, whose $\lambda$ at $25{ }^{\circ} \mathrm{C}$ values were previously known from commercial material data sheets, the CRC Handbook of Chemistry and Physics or technical data found in web sites (e.g. www.engineeringtoolbox.com).

The determined $k_{N}$ and $J$ data are shown in table 1 and the correlation between $J$ and $\lambda$ shown in figure 1 . The last property ranges from $0,0945 \quad W \quad \mathrm{~K}^{-1} \quad \mathrm{~m}^{-1} \quad(2,2,4-$ trimethylpentane) up to $0,68 \mathrm{~W} \mathrm{~K}^{-1} \mathrm{~m}^{-1}$ (water). 
Table 1: Newton's cooling parameters of different pure materials

\begin{tabular}{|c|c|c|}
\hline Material & $10^{4} k_{N} / s^{-1}$ & $J / \mathrm{kW} \mathrm{K}^{-1} \mathrm{~m}^{-3}$ \\
\hline Biodiesel (Quivel ${ }^{\circledR}$ ) & $11,3 \pm 0,8$ & $2,04 \pm 0,06$ \\
\hline Carbon tetrachloride & $11,3 \pm 0,3$ & $1,84 \pm 0,02$ \\
\hline Chevron MD3 ${ }^{\circledR}$ & $10,9 \pm 0,4$ & $1,91 \pm 0,07$ \\
\hline 1-Decanol & $9,4 \pm 0,1$ & $1,9 \pm 0,1$ \\
\hline Dibutyl phthalate & $10,8 \pm 0,2$ & $1,93 \pm 0,04$ \\
\hline Di(ethylene-glycol) & $8,5 \pm 0,1$ & $2,04 \pm 0,02$ \\
\hline Diglyme & $10,42 \pm 0,07$ & $2,06 \pm 0,01$ \\
\hline Diphenyl oxide & $11,05 \pm 0,05$ & $1,93 \pm 0,03$ \\
\hline Ethylene-glycol & $7,7 \pm 0,1$ & $1,96 \pm 0,02$ \\
\hline Ethylene-glycol $-\mathrm{H}_{2} \mathrm{O}, 20 \%$ & $6,55 \pm 0,05$ & $2,62 \pm 0,06$ \\
\hline Ethylene-glycol - $\mathrm{H}_{2} \mathrm{O}, 60 \%$ & $6,70 \pm 0,07$ & $2,46 \pm 0,02$ \\
\hline Glycerol & $7,03 \pm 0,08$ & $2,15 \pm 0,02$ \\
\hline Limonene & $12,0 \pm 0,1$ & $1,80 \pm 0,04$ \\
\hline Mineral oil & $10,6 \pm 0,1$ & $1,54 \pm 0,01$ \\
\hline Novec $7500^{\circledR}$ & $5,4 \pm 0,1$ & $1,64 \pm 0,03$ \\
\hline Propylene-glycol & $8,0 \pm 0,2$ & $2,07 \pm 0,05$ \\
\hline Ricinus communis oil & $9,1 \pm 0,2$ & $1,57 \pm 0,03$ \\
\hline Silicone oil & $12,2 \pm 0,1$ & $1,77 \pm 0,01$ \\
\hline 2,2,4-Trimethylpentane & $12,3 \pm 0,1$ & $1,75 \pm 0,05$ \\
\hline Water & $6,5 \pm 0,2$ & $2,71 \pm 0,08$ \\
\hline
\end{tabular}

Since the range of $\lambda$ values is small, one should take into account the possibility that any statistical conclusion might be deceptively justifiable. An extra data point is included for Pyrex ${ }^{\circledR}$ glass $\left(\lambda=1,05 \mathrm{~W} \mathrm{~K}^{-1} \mathrm{~m}^{-1}\right)$ in the training set. The corresponding $J$ was determined from the cooling curve of empty Pyrex $^{\circledR}$ red line $50 \mathrm{~cm}^{3}$ test tubes, analogously to the experiments with the liquid samples. The result was $k_{N}=(2,67 \pm$ $0,01) \times 10^{-3} \mathrm{~s}^{-1}$. This kinetic constant must be corrected, because now the air-tube effective contact area is $161,5 \mathrm{~cm}^{2}$, rather than 125,2 $\mathrm{cm}^{2}$ for the experiments with the liquid samples (vide supra). Thus corrected $k_{N}=$ $(2,06 \pm 0,02) \times 10^{-3} \mathrm{~s}^{-1}$ and $J=(2,06 \pm 0,02) \times$ $10^{-3} \mathrm{~s}^{-1} \times 1,98 \times 10^{3} \mathrm{~kJ} \mathrm{~K}^{-1} \mathrm{~m}^{-3}=(4,08 \pm 0,05)$ $\mathrm{kW} \mathrm{K}^{-1} \mathrm{~m}^{-3}$ ensue for the particular Pyrex ${ }^{\circledR}$ glassware used. A linear correlation was thus established between $J$ and $\lambda$ at $p<0,01\left(r_{p}=\right.$ 0,96 , Student $t_{\mathrm{obs}}=14,1$, Student $t_{\mathrm{calc}}=2,92$ ):

$$
\underset{\mathrm{K}^{-1} \mathrm{~m}^{-1}}{J / \mathrm{kW} \mathrm{K}^{-1} \mathrm{~m}^{-3}=(1,5 \pm 0,1)+(2,2 \pm 0,3) \lambda / \mathrm{W}}
$$

The uncertainties on the fitting parameters correspond to $95 \%$ certainty level.

As test of compliance, a further experiment was carried out with a liquid of low thermal conductivity: the liquid for electronics cooling $3 \mathrm{M}$ Novec $7500^{\circledR}$ with $\lambda=0,065 \mathrm{~W} \mathrm{~K}^{-1}$ $\mathrm{m}^{-1}$. The experimental values for this engineered fluid were $k_{N}=(9,0 \pm 0,2) \times 10^{-4} \mathrm{~s}^{-}$ 1 and $J=(1,64 \pm 0,03) \mathrm{kW} \mathrm{K}^{-1} \mathrm{~m}^{-3}$. The estimated $\lambda$ is $0,064 \mathrm{~W} \mathrm{~K}^{-1} \mathrm{~m}^{-1}$, a value $2 \%$ lower from that reported by $3 \mathrm{M}$. Inclusion of the Novec $7500^{\circledR}$ data pair does not change the parameters for equation [5]. 


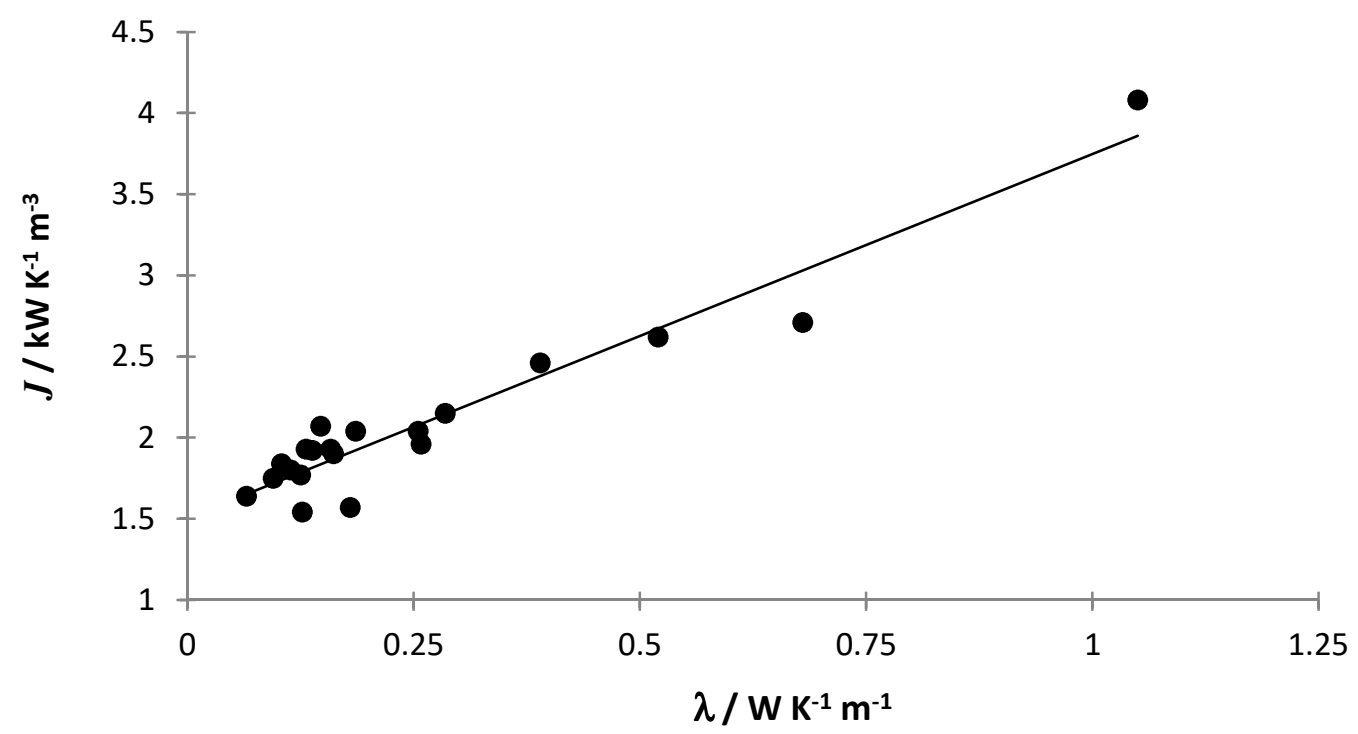

Figure 1: Test of hypothesis of correlation between $\lambda$ and $J$

$J$ values are obtained on the average with 2 $\%$ uncertainty. The maximum expected error on predicted $\lambda$ by using equation [5] is of the order of $15 \%$, for $p=0,05$. Thus, the prediction checks well.

The intercept in equation [5] should be close to the corresponding $J$ for very low heatconducting materials, such as common gases (average $\lambda=0,02 \mathrm{~W} \mathrm{~K}^{-1} \mathrm{~m}^{-1}$, exception of $\mathrm{H}_{2}$ and $\mathrm{He}$ ).

Mohanty (1951) established a relationship between the thermal conductivity of liquids and their viscosity,

$$
M \times \frac{\lambda}{\eta}=\text { constant }
$$

where $M$ is the molecular mass of the liquid material of absolute viscosity $\eta$. Thus, one can think of an analogous relationship between $J$ and $\lambda$. Figure 2 shows the $J$ data obtained to comply qualitatively with the proposal of Mohanty. Water, the two aqueous ethylene-glycol mixtures and the three Chevron "oils" are excluded, due to either extraordinary behaviour of aqueous systems or the lack of molecular mass data. 


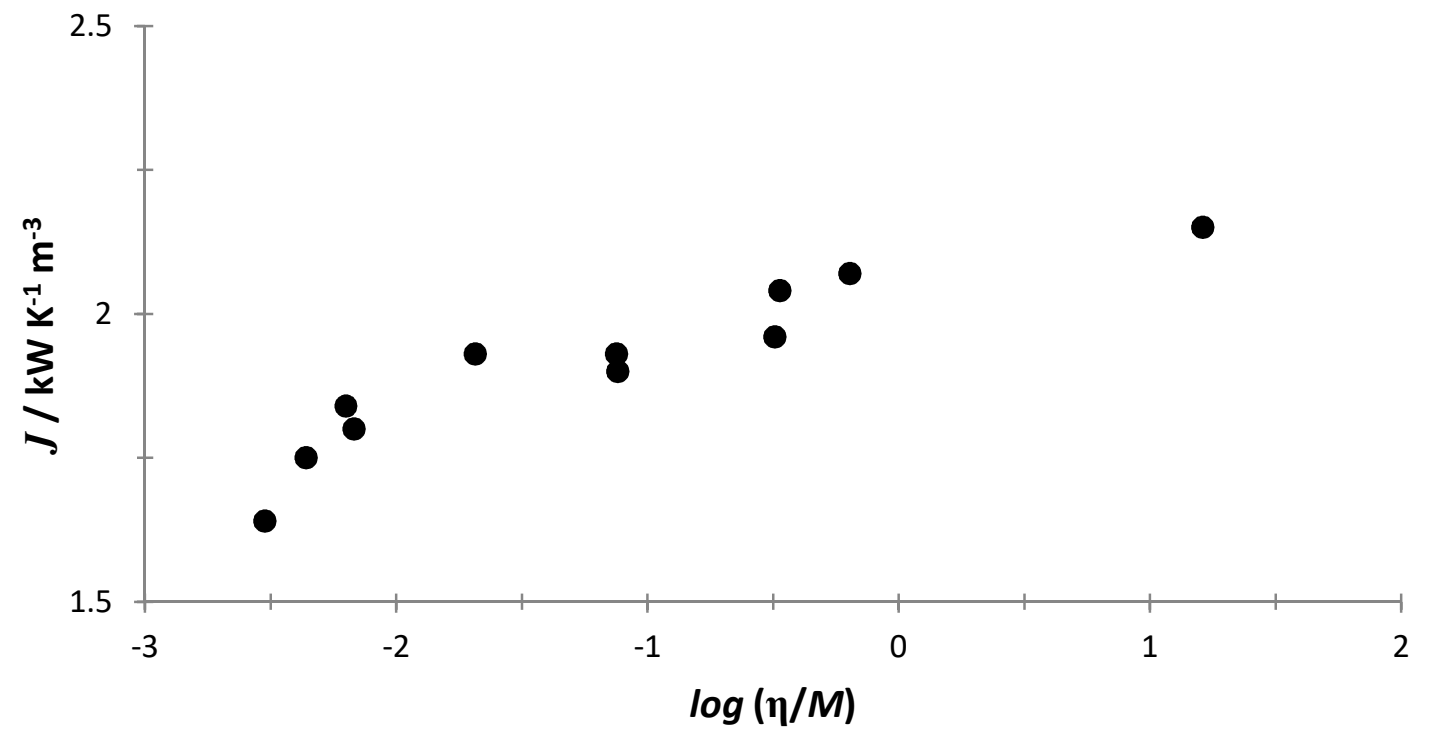

Figure 2: Correlation between $J$ and viscosity

Thus, the proposed simple model and methodology are proven to be of practical usefulness for the comparison of the heat transfer ability of liquid materials.

\section{Suitability of biodiesel and vegetable oils as heat-transfer fluids}

Table 2: Newton's cooling parameters of some long-chain industrial liquid materials

\begin{tabular}{|c|c|c|c|}
\hline Material & $10^{4} k_{N} / s^{-1}$ & $C_{p} / \mathrm{kJ} \mathrm{K}^{-1} \mathrm{~kg}^{-1}$ & $J / \mathbf{k W ~ K}^{-1} \mathbf{m}^{-3}$ \\
\hline Biodiesel (Energías Biodegradables ${ }^{\circledR}$ ) & $11,1 \pm 0,5$ & $2,8 \pm 0,5$ & $2,7 \pm 0,5$ \\
\hline Biodiesel $\left(\mathrm{H} \& \mathrm{M}^{\circledR}\right)$ & $10,4 \pm 0,1$ & $1,7 \pm 0,3$ & $1,5 \pm 0,1$ \\
\hline Acrocomia sp. oil & $9,60 \pm 0,03$ & $3,2 \pm 0,6$ & $2,6 \pm 0,5$ \\
\hline Elaeis guineensis olein & $10,93 \pm 0,08$ & 1,96 & $1,90 \pm 0,01$ \\
\hline Recuperated frying oil & $10,0 \pm 0,3$ & $3,4 \pm 0,6$ & $3,0 \pm 0,2$ \\
\hline Ricinus communis oil & $9,1 \pm 0,2$ & 1,92 & $1,60 \pm 0,03$ \\
\hline Chevron SAE $30^{\circledR}$ & $9,8 \pm 0,7$ & $1,2 \pm 0,4$ & $1,0 \pm 0,3$ \\
\hline Chevron SAE $40^{\circledR}$ & $11 \pm 1$ & $2,6 \pm 0,3$ & $2,5 \pm 0,4$ \\
\hline 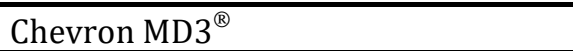 & $11,0 \pm 0,4$ & $2,4 \pm 0,7$ & $2,2 \pm 0,6$ \\
\hline
\end{tabular}

Quivel $^{\circledR}$ biodiesel was made from Elaeis guineensis oil exclusively, and the biodiesel from Energías Biodegradables ${ }^{\circledR}$ made from recuperated frying oil. $H \& M^{\circledR}$ biodiesel incorporates waste animal fat as feedstock.
Table 2 gives the $J$ values for biodiesel, some vegetable oils and petroleum-derived longchain materials available in Costa Rica. 
For the case of Acrocomia, Elaeis and Ricinus oils, the uncertainty ranges make their $J$ statistically undistinguishable. Recuperated frying oil shows a higher $J$, value that can be understood in terms of its relatively high water content $(0,17 \pm 0,02 \%$, Karl Fischer).

Chevron SAE $40^{\circledR}$ and Chevron MD3 ${ }^{\circledR}$ behave similarly. No comment is possible about the difference shown by Chevron SAE $30^{\circledR}$, because no information is available on the details of their chemical constitution, including additives.

$J$ values can be clustered around $J=(1,8 \pm$ $0,6) \mathrm{kW} \mathrm{K}^{-1} \mathrm{~m}^{-3}$ for the five petroleumderived liquids, $J=(2,1 \pm 0,6) \mathrm{kW} \mathrm{K}^{-1} \mathrm{~m}^{-3}$ for the three samples of biodiesel and $J=(2,3 \pm$ $0,6) \mathrm{kW} \mathrm{K}^{-1} \mathrm{~m}^{-3}$ for the four vegetable oils. They are statistically similar in their heattransport ability. Since we are unable to introduce the correcting effect of molecular mass, no comment is offered on the reason for the observed similar heat-conduction ability of the 12 materials.

They are all made of relatively long molecules, with similar degrees of packing. Short-range intermolecular forces have been implied to favour heat transfer in liquids (Ishii, et al., 2014, Olivares \& Anteneodo, 2016). The intermolecular force fields in the liquid state exert actions that hinder the relative motions of molecules, thus shortrange repulsions play the main role in heat conduction.

These findings indicate that vegetable oils and biodiesel derived from them have similar heat-conducting properties to be used in solar collectors or for low-enthalpy geothermal applications, in place of petroleum-derived materials.

The quenching process of materials is the rapid cooling of hot pieces when immersed in liquids such as water, oils or even air. The aim is to prevent secondary changes at low temperature that mean undesired properties of products. The cooling must be rapid, and therefore one aims to prevent undesired processes that are thermodynamically feasible and kinetically meaningful at low temperatures. Kobasko et al. (2010) studied the suitability of five vegetable oils as quenching liquids, by determining their heattransfer coefficients $(h)$ and further comparison with those of the petroleumderived oils Micro Temp $157^{\circledR}$ (a "slow" oil) and Micro Temp 153B ${ }^{\circledR}$ (a "fast" oil). The cooling processes were determined in the range from $700{ }^{\circ} \mathrm{C}$ or $450{ }^{\circ} \mathrm{C}$ down to $60{ }^{\circ} \mathrm{C}$. The triacylglycerols were found to have average $56 \%$ higher $h$ than the petro products. Thus, the authors concluded that the quenching ability of vegetable oils was higher than for petroleum-derived quenchants. Although vegetable oils show higher $J$ than those of petro-derived oils, the Kobasko et al. conclusion cannot be arrived at from our data, due to the broader uncertainty ranges of the data presented in this paper.

\section{Conclusion}

The empirical quantity $J=k_{N} \times \rho \times C_{p}$ can be used for comparison of the ability of liquid materials to transport thermal energy driven by a temperature gradient, when the value of thermal conductivity is not known. $k_{N}$ is Newton's cooling rate.

For working thermal conditions such as those of solar-collectors or low-enthalpy geothermal applications, vegetable oils and biodiesel have similar $J$ values amongst themselves, though their $J$ are only about $80 \%$ that of liquid water. This finding is nevertheless useful due to the more environmentally friendly properties of the vegetable-derived materials, relative to petroleum long-chain liquids of similar thermal conductivity.

\section{Acknowledgement}

We thank María Angélica Angulo for her contribution to the measurement of $k_{N}$ of 1decanol. The authors thank the gifts of palm olein by Palma Tica, S. A., Acrocomia oil by Green Integrated Energies, and of biodiesel samples from Biodiesel H\&M and Energías Biodegradables. A sample of Novec $7500^{\circledR}$ was a gift from Intel Costa Rica.

Fabricio Rodríguez-Acevedo, Stefano Fiore-Álvarez, Melissa Zúñiga-Campos, Bárbara C. Miranda and Julio F. Mata-Segreda (2018), International Journal of Renewable Energy and Biofuels, DOI: 10.5171/2018.996542 


\section{References}

1. Bridgman, P. W. (1923). The thermal conductivity of liquids, Proceedings of the National Academy of Sciences USA, 9, 341345.

2. Constant, F. W. (1954). Theoretical physics, vol. 1. Addison-Wesley, Reading, Massachusetts, chapter 15.

3. Demirbaş, A. (2008). Biodegradability of biodiesel and petrodiesel fuels, Energy Sources, Part A: Recovery, utilization and environmental effects, volume 31, issue 2 . DOI: $10.1080 / 15567030701521809$.

4. Ishii, Y., Sato, K., Salanne, M., Madden, P. A., Ohtori, N. (2014). Thermal conductivity of simple liquids: Origin of temperature and packing fraction dependences. Journal of Chemical Physics, 140, 114502-114504.

5. Kobasko, N. I., de Souza, E. C., Canale, L. de C. F., Totten, G. E. (2010). Vegetable oil quenchants: Calculation and comparison of the cooling properties of a series of vegetable oils. Journal of Mechanical Engineering, 56, 131-142.
6. Lutz, G., Chavarría, M., Arias, M . L., MataSegreda, J. F. (2006). Microbial degradation of palm (Elaeis guineensis) biodiesel. Revista de Biología Tropical, 54(1): 59-63.

7. Mohanty, S. R. (1951). A relationship between heat conductivity and viscosity of liquids. Nature, 168, 42.

8. Olivares, C., Anteneodo, C. (2016). Role of the range of the interactions in thermal conduction. Physical Review E, 94, 042117.

9. Osida, I. (1939). On the thermal conductivity of liquid. Proceedings of the Physico-Mathematical Society of Japan, 21, 353-356.

10.Salazar, A. (2003). On thermal diffusivity. European Journal of Physics 24, 351-358.

11.Sendzikiene, E., Makareviciene, V., Janulis, P., Makareviciute, D. (2007). Biodegradability of biodiesel fuel of animal and vegetable origin, Eur. J. Lipid Sci. Technol., 109, 493-497. 12.Shoemaker, D. P., Garland, C. W. (1968). Experimentos de fisicoquímica, Spanish ed., UTEHA: Mexico.

Fabricio Rodríguez-Acevedo, Stefano Fiore-Álvarez, Melissa Zúñiga-Campos, Bárbara C. Miranda and Julio F. Mata-Segreda (2018), International Journal of Renewable Energy and Biofuels, DOI: 10.5171/2018.996542 